\title{
Factors affecting the business performance of enterprises: Evidence at Vietnam small and me- dium-sized enterprises
}

\author{
Vu Ngoc Xuan a*, Nguyen Thi Phuong Thu and Ngo Tuan Anh ${ }^{a}$
}

${ }^{a}$ Center for Analysis Forecasting and Sustainable Development, National Economics University, Vietnam

\section{CH R O N I C L E}

\section{Article history:}

Received: September 152019

Received in revised format: Sep-

tember 292019

Accepted: October 10, 2019

Available online:

October 10, 2019

Keywords:

Profitability ability $(P A)$

Business performance $(B P)$

Enterprises (ES)

Small and medium-sized enter-

prises (SMEs)

Supporting policies (SP) \begin{abstract}
A B S T R A C T
The purpose of this study is to identify factors affecting the performance of the small and medium-sized enterprises (SMEs) in Vietnam. The research team uses a sample size of 456 SMEs. The information is collected by the authors based on the survey results and the financial statements of SMEs listed on Vietnam stock market. Descriptive statistical methods and multivariate linear regression analysis are also used in the study. The data processed through SPSS 20.0 software and the research results show that factors of access to government support policies, education level of enterprises owner, enterprises scale, society relationships of enterprises and revenue growth rate affect the business performance of SMEs in Vietnam. In addition, the study uses a multivariate linear regression model based on the least squares method to estimate the factors affecting the performance of SMEs in Vietnam. The research results also show that the performance of the enterprises is influenced by different factors: scale, growth rate, profitability, and industry cohesion of enterprises. On that basis, the article proposes some solutions to improve the performance of SMEs in Vietnam in the current period.
\end{abstract}

C 2020 by the authors; licensee Growing Science, Canada

\section{Introduction}

Speaking of SMEs refers to the ability to create jobs and income, improve business management skills, and promote entrepreneurship and creativity. In particular, SMEs play an important role in honing SMEs administration skills and promoting innovation. In addition, SMEs also help build a flexible industrial production system, with close links, exploiting and mobilizing all potentials of localities, creating a healthier competitive market and injecting positive spillover effects on the economy. Therefore, promoting the development of SMEs is considered an effective means to mobilize capital as well as other resources for production and business activities, contributing to economic growth and stability socialization. In the context of today's fiercely competitive market, in order to survive and grow, SMEs needs to be proactive and actively seek ways to increase profits in a reasonable manner. To do so, the SMEs owner first needs to have a basic awareness of the factors that affect his SME's performance. Specifically, profitability is the ratio to measure SMEs' performance, which is the main aspect of SME's financial statements. Profits of an SME show the SME's ability to generate income over a given period of time. Profitability is the deciding factor that helps managers develop an effective profitability strategy for SMEs.

\section{Research objectives}

This study is conducted to reach two objectives: (1) Analyze the current situation of business and production activities of SMEs in Vietnam; and (2) Identify the factors that affect the performance of SMEs in Vietnam. To conduct an estimation of the factors affecting the performance of small and medium-sized Enterprises (SMEs), we use secondary data using convenient sampling techniques from the 2018 Financial Statements of 456 SMES and the database based on the SMEs listed on Vietnam's stock market, with the selected analysis criteria in the model. The study uses SPSS 20.0 software to support data analysis. Descriptive statistical methods with criteria such as average, rate, frequency and standard deviation are used to analyze the current situation of SMEs' production and business activities with an adaptation of regression technique.

\footnotetext{
* Corresponding author.
}

E-mail address: xuanvn@neu.edu.vn (V. N. Xuan) 


\section{Literature review}

Through a review of several studies we understand there are many factors affecting the business performance of Enterprises in general and SMES in particular. Baard and Van den Berg, (2004), Kokko and Sjöholm (2004), Hansen et al. (2002) have shown that the size of an enterprise is one of the factors influencing the business results. According to the studies of Panco and Korn (1999) and Hansen et al. (2002), the age of an enterprise (Es) is a factor affecting the survival and development of the firm. Hansen et al. (2002) and Vu Ngoc Xuan et al. (2018) showed that the education level of the Es owner and the Government support policy has an impact on the business performance of SMES. In addition, Vu et al. (2019), once again demonstrated the level of access to government support policies affecting the business performance of Es. Social system, revenue growth are also factors affecting business performance. Therefore, in this study, the above factors were put into the analysis model by the authors to determine the factors affecting the business performance of SMES. The research model is as follows:

$$
Y=B o+B_{1} X_{1}+B_{2} X_{2}+B_{3} X_{3}+B_{4} D_{4}+B_{5} D_{5}+B_{6} X_{6}+\varepsilon
$$

where: The dependent variable $Y$ is rate of return / revenue (ROS - return on sales) of Es. Variables $\mathrm{X}_{1}, \mathrm{X}_{2}, \mathrm{X}_{3}, \mathrm{D}_{4}, \mathrm{D}_{5}, \mathrm{X}_{6}$ are independent variables (explanatory variables) defined in Table 1. From the nature of the independent variables, the model tests the influence of factors on the performance of Vietnamese $\mathrm{SME}_{\mathrm{S}}$, the authors expect the sign of the variables in the model given in Table 1. Based on the theory regarding the performance, previous literature references as well as personal views, the authors propose the following general research model:

$$
E(Y / Y t)=\beta o+\beta_{1} Y_{1 t}+\beta_{2} Y 2_{t}+\beta_{3} Y_{3 t}+\beta_{4} Y_{4 t}+\beta_{5} Y_{5 t}+\beta_{6} Y_{6 t}+\varepsilon
$$

where: The dependent variable $\mathrm{E}(\mathrm{Y} / \mathrm{Yt})$ is the return on total assets $(\mathrm{ROA})$. The independent variables ( $\left.\mathrm{Y}_{\mathrm{it}}\right)$ are respectively the scale of ES $\left(\mathrm{Y}_{1}\right)$, age of ES $\left(\mathrm{Y}_{2}\right)$, revenue growth $\left(\mathrm{Y}_{3}\right)$, profitability $\left(\mathrm{Y}_{4}\right)$, productivity $\left(\mathrm{Y}_{5}\right)$ and coherence industry $\left(\mathrm{Y}_{6}\right)$.

Specifically, the research conducted tests of the following hypotheses:

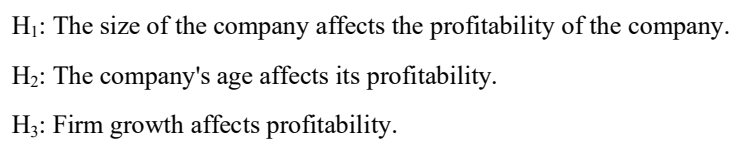

\section{Table 1}

Interpretation of independent variables in a linear regression model

\begin{tabular}{llc}
\hline Variable & Explanations & Expected \\
\hline$X_{1}$ & Number of state supports that Es has been received. & + \\
$X_{2}$ & Years of operation of Es. & + \\
$X_{3}$ & Education of owner Es & + \\
$X_{4}$ & The size of Es (Dummy variable) & + \\
$X_{5}$ & Es's social relationship (Dummy variable) & + \\
$X_{6}$ & Sales growth rate of Es & + \\
\hline
\end{tabular}

Table 2

\begin{tabular}{|c|c|c|c|}
\hline Variable & Explanations & Measure variable & Expected \\
\hline Y1 & Scale Es & Log (Total assets) & $+/-$ \\
\hline Y2 & Es age & $\log ($ Number of years of operation) & $+/-$ \\
\hline Y3 & Growth & (DT year present - Revenue of previous year) / Revenue of previous year & $+/-$ \\
\hline Y4 & Profitability of & previous profit before/ previous year & + \\
\hline Y5 & Productivity & Log(VAT / number of employees) & + \\
\hline Y6 & Calculate industry & $\log (\mathrm{VAT})$ & + \\
\hline
\end{tabular}

Expected sign of variables in the model

\section{The results}

\subsection{Current situation of SMES's production and business activities}

The operation and development situation of SMES (classified under Decree 56/2009 / ND-CP) in Vietnam is quite extensive, to find out more about the coin production problem in business. In order to assesse the status of development of Es, the authors collected information about $\mathrm{SME}_{S}$ by survey questionnaire with 24 criteria. The total number of SMES investigated is 456 Es. The data was randomly collected to ensure the truthfulness and objectivity of the survey. Regarding Es scale, if based only on the number of employees defined in Decree 56/2009 / ND-CP, the Ess are small Es type, specifically, 207 Es have the number of employees under 10 people ( accounting for 45\%); 166 Es have the number of employees from 10 to 99 people (accounting for 36\%), the rest are Es employing over 100 employees (19\%). Many Es have a moderate number of medium-sized employees, 7 Es with 100 to 199 employees and 5 Es with 200 to 300 employees. Besides, the average number of employees of Es is about 18 people, including those who only work with 2 employees, these figures are quite low compared with $\mathrm{SME}_{\mathrm{S}}$ labor criteria in Decree 56. / 2009 / ND-CP of the Government. 
According to the survey on educational attainment, more than two thirds of Es masters have been trained, of which $57.6 \%$ of Es owners have university and college degrees and $16.2 \%$ have graduated recently and created intermediate professional. In general, the education level in the research sample was quite high, which shows a favorable foundation for Es. Es owners seem to achieve higher management efficiency as well as absorb scientific and technical advances and Information in a better way. The study results also showed that the average rate of female workers in the $\mathrm{SME}_{\mathrm{S}}$ was $31.2 \%$, accounting for about $1 / 3$ of the total number of employees in Es. The use of many female workers in Es is encouraged by the government with many preferential policies, such as borrowing loans of Es with many female workers will be easier than other Es. In addition, according to research results from $456 \mathrm{SME}_{\mathrm{S}}$, an average of $58 \%$ of administrative and managerial workers have university college degrees, $42 \%$ of production and business workers have received vocational training. Thus, it can be said that the quality of labor in the Es in the research sample is quite high compared with the common ground (about 34\%). In addition, the quality of life of employees has gradually improved significantly; the average income in 2018 of SMES workers in the sample was 45,390,000 VND / year. In terms of capital size, the survey results also show that the average total capital of Es in the sample was only about VND 4.2 billion, of which, fixed assets were VND 1.3 billion. Thus, in terms of both labor scale and capital size, they were quite small compared with the common ground, they mainly focus on micro and small types. In addition, SMES rely primarily on equity. From the results of the survey, most of Es stated that equity was mainly used, specifically; $\mathrm{SME}_{\mathrm{S}}$ used an average of $73.2 \%$ of equity capital for production and business activities, and the remaining mobilization were from other sources outside. Other sources of loans exist in many forms, including bank loans, personal loans, commercial credit, etc. Among the types of loans, bank loans were accounted for the highest proportion, $48.33 \%$. Many firms made capital mobilization by borrowing from banks, $24.42 \%$ came from the supplier's commercial credits and $7.97 \%$ of them used personal loans. In particular, bank loans, on average, account for $15.59 \%$ of Es's total funding, indicating the importance of bank loans in supporting credit for SMES. Most Ess had revenue in 2018 compared with 2017, with an increase of $62 \%$; revenue decreased by $16 \%$; unchanged revenue accounted for $22 \%$ of the total Es surveyed. In addition, the profitability of $\mathrm{SME}_{\mathrm{S}}$ was quite balanced with the revenue growth. 57.1\% of Es's profits in 2018 increased compared with 2017 and only 19\% of Es's profits decreased. Through this we see a consistent growth between revenue and operating profit in 2018 of SMES, which is an especially necessary factor for joint stock companies in attracting investors.

Table 3

Descriptive characteristics of SMES in the survey

\begin{tabular}{|c|c|c|c|c|}
\hline Criteria & Mean & Max & Min & Std. Dev. \\
\hline Age of Es (years) & 4.95 & 34.00 & 1.00 & 4.54 \\
\hline Total employees (people) & 16.97 & 300.00 & 2.00 & 30.38 \\
\hline Total assets (million) & 4136.85 & 50000.00 & 20.00 & 7219.80 \\
\hline debt-to-equity ratio & 0.81 & 16.45 & 0.00 & 1,55 \\
\hline revenue (million) & 6555.12 & $196,189.00$ & 11.00 & $103,475.13$ \\
\hline profit (million) & 434.20 & 21281.00 & -500.00 & 1369.73 \\
\hline turnover total assets & 2.48 & 39.24 & 002 & 4.57 \\
\hline Rate of return $(\%)$ & 13.00 & 139.00 & -83.00 & 23.00 \\
\hline
\end{tabular}

In addition, the average Debt to Equity Ratio (D/E) of Es in the sample survey is $0.81<1$ which may indicate that Es is less dependent on the form of capital mobilization by borrowing. However, this may also indicate that Es does not know how to borrow to do business and exploit the benefits of tax savings. Another point worth noting is that the average total asset turnover of the $\mathrm{SME}_{\mathrm{S}}$ in the sample is quite high (2.48), which shows that the efficiency in using the entire Es's total assets is good. It can be said that, despite being affected by the China American trade war, significant $\mathrm{SME}_{\mathrm{S}}$ efforts exists in managing and operating. However, in the process of economic recovery and development, the SMEs actually encountered many difficulties, such as the situation of investment expansion and market promotion of SMES in Vietnam still faces many droughts. In particular, only about one-third of Es did this in 2018, and there is also a lack of information, including information about the market, competition, and support policies of State for SMES,

\subsection{Factors affecting the business performance of SMES}

\section{Table 4}

Results of the analysis model of linear regression

\begin{tabular}{|c|c|c|c|c|c|}
\hline & & Beta & Std. Beat & Sig. & VIF \\
\hline Constant & & -0.198 & & 0.000 & \\
\hline TCCSHT & $\mathrm{X} 1$ & 0.040 & 0.321 & 0.000 & 1.145 \\
\hline TUOIES & $\mathrm{X} 2$ & 0.004 & 0.131 & 0.005 & 1.056 \\
\hline HOCVAN & $\mathrm{X} 3$ & 0.060 & 0.370 & 0.000 & 1.240 \\
\hline QUYMO & D4 & 0.030 & 0.110 & 0.018 & 1.058 \\
\hline VONXAHOI & D5 & 0.049 & 0.142 & 0.002 & 1.059 \\
\hline TANGDT & X6 & 0.042 & 0.097 & 0.034 & 1.025 \\
\hline
\end{tabular}

The results of the linear regression analysis are as follows: (1) Observed significance level Sig. very small (Sig. $=0.00)$ shows that the security level rejects the Ho hypothesis, which means that there exists a linear relationship between the business performance of Es (measured by the rate of profit) with, at least, one of the factors being an independent variable, such a linear regression model is given in accordance with the data. 
The Adjusted R-Square value is smaller than the $\mathrm{R}^{2}$, so it should be used to evaluate the model as more suitable and it does not inflate the model suitability, so adjusted $\mathrm{R}^{2}=0.60$ means that $60 \%$ of Es's business performance can be explained by the linear correlation between SMEs' profit margin and the independent variables included in the model. The Durbin-Watson coefficient of the model is 1.916, indicating that the model has no autocorrelation phenomenon. In addition, the variance magnification (VIF) of the variables in the model is much smaller than 10 , so we conclude that the variables included in the model do not have multi-collinear phenomena. Of the 6 variables included in the model, all 6 explain the change in business performance of $\mathrm{SME}_{S}$. In particular, the variable $\mathrm{X}_{1}$ (the number of state supports that Es has been received) has a positive effect on the business performance of $\mathrm{SME}_{S}$, showing the importance of this factor to production activities. Es's business is huge, which fits perfectly with the argument that the authors originally made. In fact, in order for Es's business operations to be effective and convenient, Es need to take advantage of inherent resources including human, material and financial resources. The other important thing is to learn on how to exploit the necessary support that the state has set out in the SMES development support policies, the more Es can exploit the various forms of state support related to its activities, the more Es can easily improve the capacity and resources for the operation of Es to develop more smoothly. In addition to the impact of access to state support policies, the variable $\mathrm{X}_{2}$ (the number of years of operation of Es) is also an important factor positively affecting the efficiency of production and business activities. SMES that have been operating for a long time can accumulate a lot of capital to finance their business activities as well as new investment projects. At the same time, because they have been operating for a long time, these Ess have a lot of experience, have created credibility and extensive social relationships with other Es or with commercial banks, because of easy access the capital as well as information related to their operations, so the performance is also high. The variable $\mathrm{X}_{3}$ (education level of the owner Es) is also positively correlated to the performance of Es. The higher the educational level, the more Es owners are able to access modern management science methods to help the company grow more and have more opportunities, while having a broader, more knowledgeable relationship about institutions, more policy regulations. The coefficient of factor $\mathrm{X}_{4}$ (scale Es) bearing a positive sign $(+)$ indicates that smaller firms have better production and business efficiency than micro Es. The reason is that small or mediumsized Es has better capital, labor, and wider market size, which contributes to good business support. At the same time, the increase in scale will help Es increase production to meet timely demand when there is a shortage of supply in the market and thus will increase sales and profits for the Es. Similarly, the $X_{5}$ variable (Es's social relationship) also has a positive coefficient with the performance of $\mathrm{SME}_{\mathrm{s}}$. This proves that social relationships also affect Es's business performance. When the Es owner has a relationship with some association, the credit institution will increase his / her reputation, increase the access to relevant information such as market, technology, labor, policies, etc. At the same time, when there are difficulties in the operation process, these Es can support each other through assistance in capital, facilities and technology transfer. The positive influence of the variable $\mathrm{X}_{6}$ (the revenue growth rate of Es) shows that the Es had a better revenue growth, higher production and business efficiency since their revenue growth reflects their economic potential, stability and growth. This is entirely consistent with reality. In summary, the research results show that besides the impact from the environment within Es, the level of support from the state is also a very important factor affecting business performance. Therefore, the key issue now is how to enhance the accessibility of state support policies for SMES in Vietnam, thereby promoting the effectiveness of SMES support in government.

\subsection{Factors affecting the performance of ES}

The statistical value $F$ is meaningful when the level of significance is 0.000 which rejects the null hypothesis, meaning that the relationship exists. The coefficient of determination of $\mathrm{R}^{2}$ is $54.9 \%$, which is quite reasonable, showing that the general fluctuations of the affecting factors explain about $54.9 \%$ of the $\mathrm{SME}_{\mathrm{S}}$ performance. The non-measurable portion of the regression model here is about $45.1 \%$ due to the impact of other important factors on the performance of the firms, but since it is not quantifiable, some factors cannot be included in the model regression such as: Leadership level, gender, volatility situation of the economy, Government policies, etc. Specific results of each variable are as follows,

\section{Scale of ES - Y1}

Scale of ES, with an estimated value of $\beta_{1}=-0.03$ (0.001) shows that, when the ES scale increases by $1 \%$, the ROA will decrease to $0.03 \%$. The results of this study are consistent with the studies of Ramasamy and Yeung (2005), Salman and Yazdanfar (2012) and Margaretha and Supartika (2016). The larger ES may have difficultly to effectively manage the organizational structure, from overcoming bureaucratic issues in the management structure. On the other hand, the fact shows that the smaller the ES scale, the higher the profit level. Most SMES in the province of Thua Thien - Hue in particular and the country in general have a modest value of total assets due to thin capital. With this "modesty", ES leaders need to have proper strategies in selecting markets, appropriate technologies and competitive strategies. For example, ES can hire tools or technology from another ES to support the manufacturing process, thus, they will reduce the cost of buying assets, thereby making the production more efficient, thus ES can make a higher profit.

Age of ES - Y2

Age of ES does not significantly affect returns since the value of $\beta_{2}$ is insignificant $(\beta 2=0.007$ sig. $=0.70)$. This result is consistent with the research of Malik (2011) and collaborative research between Mehari and Aemiro (2013). Research shows that long-term ES would not necessarily mean higher profits. In contrast, newly established ES have more advantages, reflected in innovation and application of new technology, advanced technology, access to more information, knowledge and opportunities than active ES perennial cave. 
Table 5

The results of analysis of linear regression model

\begin{tabular}{|c|c|c|c|c|}
\hline indicator & Variable & Coefficient influence $(\beta)$ & coefficient of influence ( $\beta$ eta) & Value probability \\
\hline Constant & & .079 & & .027 \\
\hline Scale Es & $\mathrm{X} 1$ & $-.030 *$ & $-.381 *$ & $.001 *$ \\
\hline Age of Es & $\mathrm{X} 2$ & .007 & .034 & .703 \\
\hline Growth & $\mathrm{X} 3$ & $.016 *$ & $.225 *$ & $.020 *$ \\
\hline Profitability & $\mathrm{X} 4$ & $.551 *$ & $.428 *$ & $.000 *$ \\
\hline Productivity & X5 & .015 & .102 & .281 \\
\hline Industry cohesion & $\mathrm{X} 6$ & $.020 *$ & $.202 *$ & $.040 *$ \\
\hline
\end{tabular}

Coefficient $\mathrm{R}^{2}=0.549 *$ Durbin Watson coefficient $=2.229 *$ F-value $=18.888 *($ Sig. $=0.000)$

Source: compiled by the authors

Revenue growth - Y3

The growth of ES has positive effects on profitability with an estimated value of $\beta_{3}$ of 0.016 (sig. $=0.02$ ). That is, when the ES scale increases by $1 \%$, the ROA will increase to $0.016 \%$. The results of this study are in line with the studies examined by Vijayakumar (2011), Salman and Yazdanfar (2012) and the research of individual Yazdanfar (2013). According to the World Bank, also in line with modern economic theory, SMES are very important for a country's economic growth and development. $\mathrm{SME}_{\mathrm{S}}$ can promote more jobs than the big ES. SMES have a smaller scope so it is easier to set up and organize ES activities. The more effective the SMES is, the more likely to increase profit.

Past profitability - Y4 Past

Profitability has a positive impact on profitability at the present time with a $\beta_{4}$ coefficient of 0.551 (sig. 0.000 ). That is, when the ES scale increases by $1 \%$, the ROA will increase to $0.551 \%$. The results of this study are consistent with the studies of Stierwald (2009), Vijayakumar (2011), Salman and Yazdanfar (2012) and individual research Yazdanfar (2013).

Productivity - Y5

The results indicate that the labor productivity of ES does not affect the profitability of ES. The results of this research is different from the one tested by Stierwald (2009), Salman and Yazdanfar (2012) and the research of Yazdanfar (2013) which shows that the company's productivity has positive impact on profits. The result is inconsistent with the previous research of the authors mentioned, but partly reflects the actual situation of SMES activities in Thua Thien - Hue province in particular and in Vietnam in general. Therefore, this variable has not really had a significant impact on profit improvement.

Sectorial Linkage - Y6

Sectorial linkage that affects profitability with an estimated value of $\beta_{6}$ is 0.02 (sig. 0.04). That is, when the ES scale increases by $1 \%$, the ROA will increase to $0.02 \%$. The results of this study are consistent with previous studies that have been verified by Vijayakumar (2011), Salman and Yazdanfar (2012) and individual research by Yazdanfar (2013).

The results of linear regression analysis in Table 2 show four variables: Scale ES $\left(\mathrm{X}_{1}\right)$, growth $\left(\mathrm{X}_{3}\right)$, past profitability $\left(\mathrm{X}_{4}\right)$, and industry cohesion $\left(\mathrm{X}_{6}\right)$ have some impacts on ES effectiveness. In particular, growth $\left(\mathrm{X}_{3}\right)$, past profitability $\left(\mathrm{X}_{4}\right)$ and industry cohesion $\left(\mathrm{X}_{6}\right)$ have positive impacts while ES $\left(\mathrm{X}_{1}\right)$ scale has a negative impact on ES performance. This study also shows that past profitability and ES scale are the two most powerful determinants of profitability. The other two variables, age of ES $\left(\mathrm{X}_{2}\right)$ and productivity $\left(\mathrm{X}_{5}\right)$, have almost no effect on the performance of these ES.

Table 6

Summary of the results of multivariate regressions

\begin{tabular}{lcccccc}
\hline Hypothesis & Company size & Age of the company & Growth & Profitability in the past & Productivity & Industry Links \\
\hline Results $\left(\mathrm{H}_{0}\right)$ & Reject & Accept & Reject & Reject & Accept & Reject \\
\hline
\end{tabular}

\section{Solutions to improve the business performance of enterprises}

For Enterprises (Es)

The main goal of ES is to maximize profits. To further improve the effectiveness of ES, ES leaders need to focus on promoting a number of positive factors and improving those that have negative impacts or currently have no impact on ES profits. The $\mathrm{SME}_{S}$ should apply incentives to improve knowledge, technical qualifications, management with bonuses based on the results of work and creativity of employees to encourage employees to go to school. In addition, they need to focus on creating a good working environment in the workplace, making employees feel rewarded, thereby being more loyal and devoted to ES, increasing their productivity and bringing profits for the company. The owners and managers need to improve their qualifications and management. The ES should develop the capital plan needed for training, improve the qualifications of ES owners and employees, focus on training the necessary skills for managers. SMESs need to attach importance to collecting market information to conduct market research effectively, at the same time, providing the resources needed to understand customer needs or follow up with competitors. SMEs need to focus on improving the technological process, not only applying advanced technology and modern machinery but also researching to improve the production process, save raw materials, minimize wastage, damage of the product, etc. in order to reduce the price and improve the competitiveness of the product. 
For the ones that ES does not work well, it is advisable to hire and transfer to other ES to take advantage. For example, if ES is in charge of managing a warehouse of its finished products in another location, the delivery to customers from that warehouse is ineffective, thus they need to hire a company specializing in warehousing, transportation services for cost savings. SMES need to have a good business orientation and a feasible business plan, suitable with the capacity and meeting the needs of the market. Accordingly, in order to sustain in the context of an increasingly deep and integrated economy, SMES need to quickly find a way to adapt to a new business environment. SMEs need to step up their cooperation, conduct mergers and acquisitions to improve their competitiveness; increase their relationships with other parties such as suppliers or distributors to help manage access control. This is also a factor that can increase the standard of quality products, to attract consumers.

\section{For regulators}

One of the ways to promote the $\mathrm{SME}_{\mathrm{S}}$ in the future is that the government should expand regulations to encourage ES development in the form of government policies such as laws and regulations. Involving SMES from the manufacturing and banking sides, such as a special credit program with terms that are not too stringent for $\mathrm{SME}_{\mathrm{S}}$, helps improve the capital base, through the service sector, formal finance, informal financial services sector, schemes, rentals, and venture capital funds. Along with that, firms need to continue to create a favorable business environment through creating a favorable legal corridor, a safe business environment, as well as simplifying licensing procedures, tax reduction, etc.

\section{Conclusion}

SMEs with the level of investment is not large, flexible and very suitable for developing private economy. These firms play an appropriate and effective way to mobilize resources from the people for economic development. Particularly for Vietnam, the development of the current SMES does not fully meet the requirements of socio-economic development, SMES often operate with the goal of introverting, within a small space. The competitiveness is still weak. The results of the study have shown that factors such as the level of access to government support policies, education of the Es owner, the size of the Es, the social relations of Es and the rate of revenue growth affect the business performance of SMES. Through the research results, the authors expect that the concerned departments and agencies will soon implement action programs to develop $\mathrm{SME}_{S}$, contributing to the country's socio-economic development. Using the least squares estimation method in the multivariate regression model, the study estimated and identified the factors affecting the performance of ES including: ES scale, increase growth, past profitability, and industry cohesion. The research results have shown that the longer time ES has been on economy, the less effective the activities are. In contrast, the growth rate, profitability of the previous year and industry cohesion almost had positive impacts on the performance of ES.

\section{Acknowledgement}

This research is funded by National Economics University, Hanoi, Vietnam.

\section{References}

Kokko, A., \& Sjöholm, F. (2004). The Internationalization of Vietnamese SMEs, Stockholm School of Economics. Asian Economic Papers, 4(1), 12-39.

Baard, V.C., \& Van den Berg, A. (2004). Interactive information consulting system for South African small businesses: part 1. South African Journal of Information Management, 6(2), 39-50.

Hansen, H., Rand, J., \& Tarp, F. (2018). SME growth and survival in Vietnam: Did direct government support matter? Institute of Economics Discussion Paper No. 04-13, Copenhagen: University of Copenhagen.

Mehari, D., \& Aemiro, T. (2013). Firm specific factors that determine insurance companies' performance in Ethiopia. European Scientific Journal, 9(10), 245-255.

Panco, R., \& Korn, H. (1999). Understanding factors of organizational mortality: considering alternatives to firm failure. có thể xem tại http://www. eaom. org.

Ramasamy, B., Ong, D., \& Yeung, M. C. (2005). Firm size, ownership and performance in the Malaysian palm oil industry. Asian Academy of Management Journal of Accounting and Finance, 1, 181-104.

Salman, A. K., \& Yazdanfar, D. (2012). Profitability in Swedish Micro-Firms: a quantile regression approach. International Business Research, 5(8), 94-106.

Stierwald, A. (2009). Determinants of firm profitability-the effect of productivity and its persistence. Melbourne Institute of Applied Economic and Social Research, 1-25.

Vijayakumar, A. (2011). An empirical study of firm structure and profitability relationship: The case Of Indian automobile firms. International Journal of Research in Commerce, IT and Management, 1(2), 100-109.

Vijayakumar, A. (2011). The determinants of profitability: An empirical investigation using Indian automobile industry. International journal of Research in Commerce and Management, 2(9), 58-64.

Xuan, V., Thu, N., \& Anh, N. (2020). Factors affecting support services in small and medium enterprises: Evidence from Vietnam small and medium information technology enterprises. Management Science Letters, 10(2), 303-312.

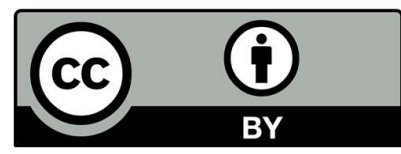

(C) 2020 by the authors; licensee Growing Science, Canada. This is an open access article distributed under the terms and conditions of the Creative Commons Attribution (CC-BY) license (http://creativecommons.org/licenses/by/4.0/). 